\title{
INSTITUTIONALISM AS A SPECIES OF EVOLUTIONISM
}

\author{
DINGA Emil ${ }^{1}$ \\ ${ }^{1}$ Romanian Academy, Bucharest, Romania, emildinga2004@gmail.com
}

\begin{abstract}
The paper aim is to examine the logical and epistemological bases of the institutionalism (especially of the economic institutionalism) in order to show that it is, in fact, a species of evolutionism (including of the economic evolutionism or of the Evolutionary Economics). The analysis will be driven from the perspective of axiomatic theories as Economics should, probably, be grounded. Among others, the paper tries to demonstrate that the institutionalism as a species of evolutionism is part of Political Economics (as normative theory) but not at all a part of Economics (as positivist theory). In the end of the study, the concepts of ethics and of morals, respectively (which are explained to be vastly different from each other) are introduced in discussion and shown they are important ingredients regarding the institutionalism as a species of evolutionism. It seems further considerations in the perspective of considering institutionalism as component part of evolutionism could be of scientific interest.
\end{abstract}

KEY WORDS: institutionalism, evolutionism, logics, epistemology, historicism

\section{PREAMBLE}

The paper aims to examine the institutionalism in the economic field from the perspective of general evolutionism, in order to show that it is a species of the latter. Moreover, it is be discussed the presupposition that the economic institutionalism is closer to Political Economics than to Economics, that is, it is closer to a normative economic theory than to a positive one. Neither the historical perspective nor descriptive one is used in the research, but rather a logical "consensus" verification between the concepts put under examination. Claiming Political Economics as vehicle for the economic institutionalism (and, of course, for the economic evolutionism or evolutionarism) implies calling to the bar of ethics (and morals, as being very distinct from ethics). The "secret" aspiration of the paper is to induce the assumption that the embedding concept of re-shaping the economic theory from an ethical (that is, humanistic) perspective is precisely the evolutionism, more exactly, a socialized species of evolutionism, based, this time, on memes and semes as socialized equivalents of genes from Biology. In fact, as will be shown and, I hope, proved, the institutionalism is an evolved way to replicate the social phenotype, that is, the social norm, in a sui generis autopoiesis of the society.

\section{PAPER'S OBJECTIVES}

The paper has three objectives to accomplish: a) to show that the economic institutionalism is a species of economic evolutionism; b) to connect the economic institutionalism to Political Economics; c) to integrate ethics and morals into the economic institutionalism (in fact, economic evolutionism).

\section{METHODOLOGY}

The methodology used in conducting the research is, preponderantly, a logic one, especially based on sufficient predicates as general framework of defining the concepts. In fact, any distinctions or similitudes of these concepts are identified and characterized using the logical comparisons between the sufficient predicates concerned. Depending on the particular points, an institutional approach will be, also, included in the general method of research developing.

\section{RESEARCH ORGANIZATION}

The research is organized on six issues which are (logical and chronological) ordered depending on their conceptual potential to bring clarifications in respect to the objectives aimed: a) introducing the general concept of institutionalism, especially from the economic field perspective; b) framing the concept of evolutionism, particularly from its socialized "species"; c) a "mirrored" examination of Political Economics and (orthodox) Economics; d) trying to show that institutionalism is the core of Political Economics; e) drawing the very objective of paper, namely bringing the arguments for accepting institutionalism as a species of evolutionism in the economic field; f) putting together the three basic concepts discussed: Political Economics, institutionalism, evolutionism.

\section{DISCUSSION}

\subsection{Institutionalism}

Generally, an institution (Hodgson, 2004) is a rule of behaviour for individuals (by extension, for communities or organizations, as well). The behaviour concerned can target any of such behaviour: praxiological (e.g. economic interactions), practical (e.g. religious interactions), theoretical (e.g. scientific activity), etc., no matter whether the institution in case if or is not formal (i.e. codified). Although, in fact, rules of behaviour are working also in nature - the instinct and the memes are the most known such systems of rules -, the concept of institution is "reserved" for cultural societies, like human one. In this frame, the behaviour, or system, or process that is functioning (preponderantly) based on institutions must be called an institutional entity. Obviously, any human society is an institutional society once the social contract is agreed. In my opinion, the sufficient predicates for institutionalism as concept are the following:

- (ID) deliberativeness: institutionalism is a deliberative designing of social interaction (including cooperation, but competition as well, e.g. the war);

- (IL) lamarckian replication: institutionalism (or, more precisely, the institutional framework, including institutional network) is replicated, among generations (or, likewise, temporally) based on the actually acquisitions in applying the institutional background concerned; this means that the randomness in the 
"mutations" of the institutional "genes", although is not totally eliminated (particularly regarding the memes, that are, generally, non-codified) is drastically mitigated - in fact, the replication or reproduction of the institutionalism is rather a (continuous) intellectual project, than a random event;

- (IF) mutual fetality of reactions norms: institutionalism, as normative property of the society, is both the cause and the effect of society development. Thus, between society as such and its institutional framework mutual reaction norms are working, so the two "partners" run shoulder to shoulder. As it will be shown further, such a dynamic partnership implies what I shall name fetality of mutual reaction norms, that is, the potential of them to build up mirrored niches in each other which are and maintain compatible in a desirable horizon of time.

In a formalist expression, the institutionalism $(I)$ is generated by the truth of conjunction of the three sufficient predicates (which means, as known, the truth - to be mentioned that, here, the truth does not means the correspondence-truth, but the simple existence (proved by verification) of each of the sufficient predicates concerned):

$$
I \leftarrow(I D) \wedge(I L) \wedge(I F)
$$

I think this $R L C$ model of institutionalism has sufficient potential to give the concept concerned the logical profile aimed at to bring it to a clarity and simplicity that ensure a clear reasoning and judgment in the matter of relationship between institutionalism and evolutionism. In fact, any examination of this relationship will be "transferred" towards an examination of the way and intensity with which the sufficient predicates accepted are implied in the concerned relationship.

Thus, we come to the concept of institutionalism: a (social) theory that has as grounding principle the institutionally functioning and regulation of behaviour.

\subsection{Evolutionism}

Economic thinking gradually and inexorable make a transition from Mechanical approach of Economics to an Evolutionary one (Hamilton, 2017). Nonetheless, such a transition is not outside of strong controversies and polemics (Aruka, 2001). Evolutionism is, in my opinion, a species of theory of becoming. However, why would we need for a genus for the species called evolutionism? I shall provide some considerations below:

- firstly, it is needed to convoke three inter-related concepts: increasing, developing, evolving, all of them being species of the genus named becoming;

- $\quad$ increasing means a simple dimensional augmentation (generally through addition processes), under maintaining as invariant the structure;

- developing means the structure variation (no matter the signification - good or bad - of such a variation), often as result of increasing, but enough often outside of increasing, by other ways of modifying the structure;

evolving (or evolution) means a permanently self-adjusting of the structure under the interactions with the environment - here it is still valid ("true") the Darwinism, that is, the assumption according with the structure causes the function (while, as we shall see further, Lamarckism has as assumption the opposite, that is, the function causes the structure.

Some conclusions based on the above considerations can now be drawn, regarding any entity: (a) increasing can occur without occurring of developments or evolving;

development can occur either as effect of increasing - the wellknown qualitative jump caused by quantitative accumulation (that is, produced above a given threshold) - or autonomously in respect with increasing (the most relevant part of my paper consists precisely in this latter way of arising the developing);

(b) evolving is, logically, a development (that is, a structure variation) induced by the interactions between entity and its environment.

Before identifying the sufficient predicates of the evolution, I would synthesize the results obtained by now regarding the three concepts put under analysis (Figure 1).

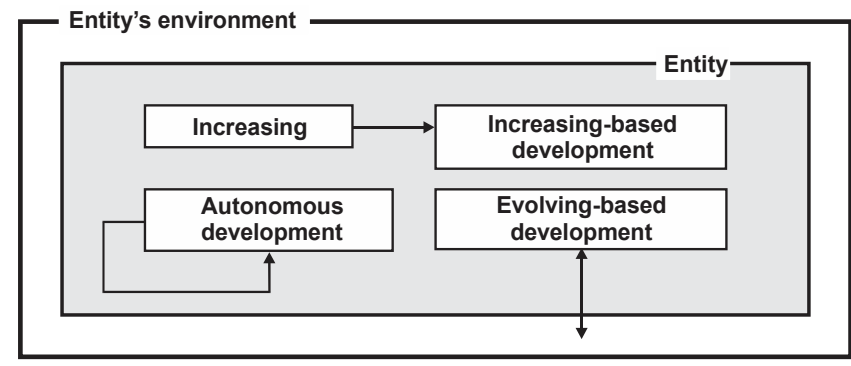

Figure 1. The three inter-related concepts around evolution, leading to three kinds of development

Source: author

So, there are three kinds of development: a) an autonomous development - this kind of development is generated, massively, by changes in the normative codified framework of the society (semes), and, in a much less extent, by own changes in its memes; b) increasing-based development - this kind of development is generated by the very logic of relationship between increasing of entity's sizes and structural changes in that entity. More exactly, the increasing inside a given structure continues (and accumulates itself) as long as the structure concerned "allows" this increasing. Above a threshold of increasing's accumulation (that is, quantitative accumulation), the given structure cannot any more sustain that increase and needs to change, that is, a development (qualitative jump) occurs within the entity; c) evolving-based development - this kind of development is generated by the relationships (inputs - outputs) between the entity and its environment, by intermediation of the mutual reaction norms. In order to integrate the impulses came from environment, the entity must often change its structure (that is, must develop itself - of course, in the mirror, the environment concerned must proceed likewise).

Now, the sufficient predicates of an evolutive process (i.e. evolution) can be identified (as minimal set of logical descriptors of that concept) as following:

- $(E F)$ finality - the structure variation (that is, the evolution) occurs under the logic of necessity. This necessity makes room either through laws or through contingency (in fact, the things happen, most probable, as follows: a necessity triggers a (temporary) line of contingency (I would name this as contingency inside necessity), and, in turn, the contingency triggers a (temporary) line of necessity (I would name this as necessity inside contingency). Thus, evolution could be understood as a permanent exchange of relay race between necessity and contingency, without any plan of any kind and of any ontological or epistemic 
authority); as laws could be either natural or positive (the latter being, thus, artefacts), and contingency can arise either under law or outside them, I believe that finality can come into existence either un-planned (if we do not think there is a sui generis such a plan) or planned; of course, the planned contingency endows the finality with purposes;

- (ED) Darwinian structuring - (I remind that Darwinism means two principles: a) random mutations on genes (biological vehicles of phenotype replication), without path arrow; b) cumulative natural selection of mutations which have occurred, with path arrow) - the pressure towards structure changes comes randomly, both for entity and for its environment, that is, outside a pre-existent model of rationality. This means, inter alia, that evolution is not a rational or purpose-based process, but a random one (we must be permanently aware that randomness means non-determinacy only, but not un-causality at all. In this context, randomness is hugely different from stochasticity, because the latter has both causality and statistical determinacy);

- $\quad($ EM) mutually adjustment of niches between entity and its environment - both entity and its environment are defined and constructed, by mutual trial and errors (in fact, a permanent fumble) between each other, so that those niches accomplish as good as possible the needed functions (for example, the entity's survival). It must be said that the environment itself is, in turn, an entity whose environment is the given entity. Thus, the development based on mutual adjustment of niches could equally be seen from the perspective of entity as from the perspective of environment as well;

In a formalist expression, the institutionalism $(I)$ is generated by the truth of conjunction of the three sufficient predicates (which means, as known, the truth of each of the sufficient predicates):

$$
E \leftarrow(E F) \wedge(E D) \wedge(E M)
$$

Thus, we come to the concept of evolutionism: a theory that has as grounding principle the structurally functioning and regulation of behaviour (it must be understood the term behaviour in its largest meaning, not only regarding the human beings and even not only the living entities (for example the geological becoming should be put under the concept of behaviour as well).

\subsection{Institutionalism as a species of evolutionism}

Based on the sufficient predicates identified (from which the definitions have been extracted) I shall now proceed to get the purpose of paper, namely, to prove that institutionalism is a species of evolutionism. To this end, two restrictions on the sphere of discussion must be introduced: a) only the human society will be considered; b) only the economic process/activity will be analysed.

In order to identify the relationship between institutionalism and evolutionism, it is very productive to put face to face their sufficient predicates. Towards this logical analysis, Figures 2 and 3 could be of usefulness by showing the possible overlapping or functional relationships among the sufficient predicates concerned.

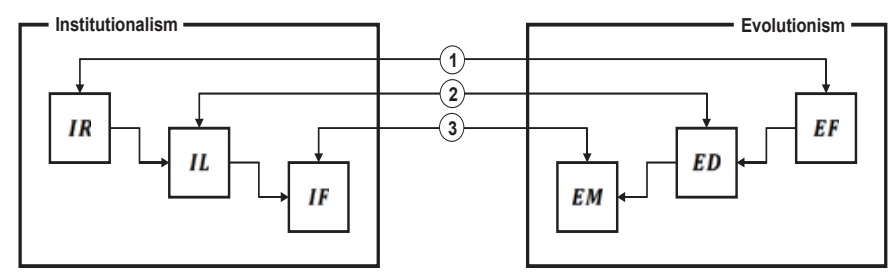

Figure 2. General relationships between institutionalism and evolutionism, through specific sufficient predicates

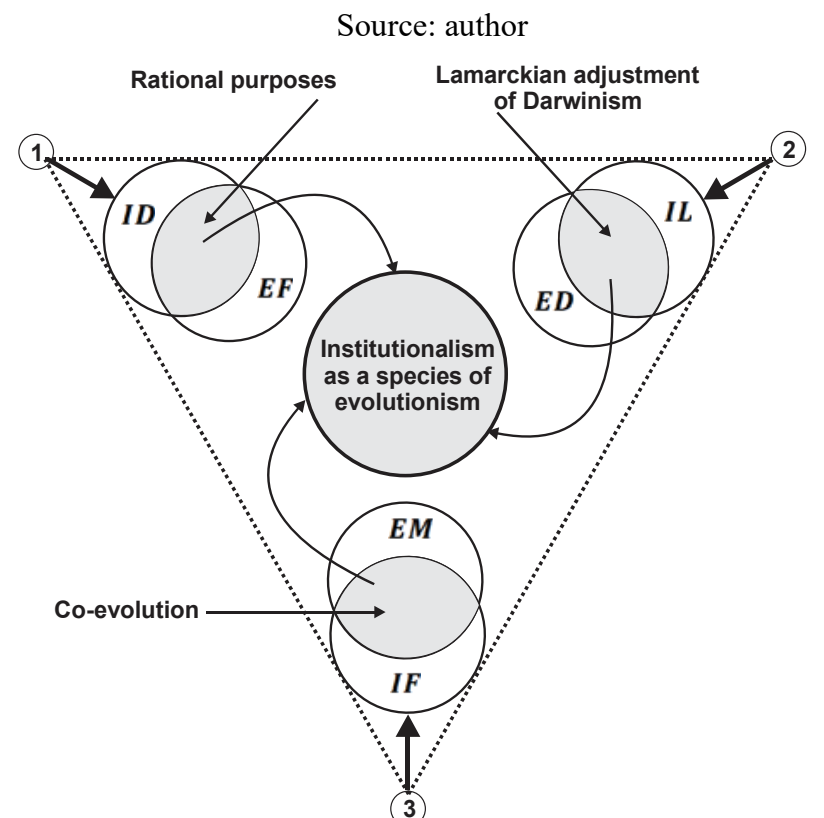

Figure 3. Intersection among the sufficiency predicates of institutionalism and evolutionism, respectively

\section{Source: author}

The reasoning based on which is proved that institutionalism is, conceptually (i.e., semantically, or as denotation) a species or a sub-sphere of the evolutionism is developed as following:

- $\quad I D \rightarrow E F$, so $I D \subset E F$, and $(I D) \cap(E F)=R P$, where with $R P$ are noted the rational purposes. For that any rational behaviour is a species of finality behaviour (as said before, the term behaviour should be considered in its largest meaning). In other words, the $I D$ sufficient predicate of institutionalism implies the $E F$ sufficiency predicate of evolutionism, so, from the perspective of these sufficient predicates, institutionalism is a species of evolutionism. From logical point of view, it must be shown that the inverse inclusion is false, that is $E F \not \subset$ $I D$ is true. Indeed, if $E F \not \subset I D$ would be false, this would mean that any behaviour finality-driven is, at the same time, a behaviour rationality-driven, which is, obviously, false. However, as it results from the intersection of the two sufficient predicates' spheres, there is finality-driven behaviours which are rationality-driven behaviours as well;

- generally, $\quad[(I L \nrightarrow E D) \wedge(E D \nrightarrow I L)] \rightarrow(I \rightarrow$ $E) \wedge(E \nrightarrow I)$. This is true for a synchronic point of view. However, a diachronic perspective says otherwise. Figure 4 help us to understand this a little bit more complicated logical relationship between the two sufficient predicates involved. 


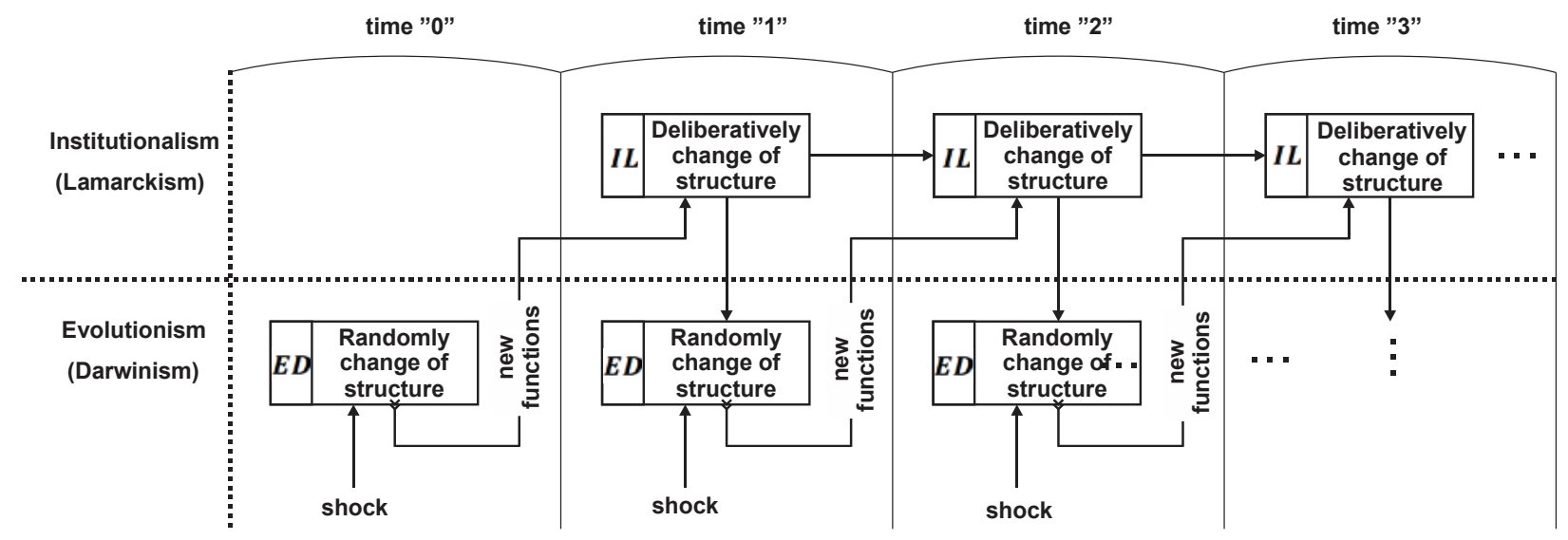

Figure 4. Intersection among the sufficiency predicates of institutionalism and evolutionism, respectively

Source: author

So, although there are not total direct logical implications between $I R$ and $E F$, however, a causal relationship persists between them: when a random shock changes (inside the evolutionism) the structure in a Darwinist way, this change generates changes (inside the institutionalism) in the functions on the entity concerned which, in turn, based on Lamarckian mechanism, leads to changes into the structure which, in the next process, takes over such changes together the new impulses from the evolutionism and so on;

- $\quad I F \rightarrow E M$, so, $I F \subset E M$, and $(I F) \cap(E M)=C E$, where with $C E$ is noted the process of co-evolution between entity concerned and its environment. Indeed, any fetality of the mutually reactions norms between entity and its environment leads to creating of the reciprocal niches in the two partners, which, in fact, are building up on each other. The common core of these reciprocal reactions constitutes the very content of the concept of co-evolution. Thus, the co-evolution is working both in the "territory" of evolutionism and in that of institutionalism, exactly at the intersection of the two correlated sufficient predicates concerned, $I F$ and $E M$, respectively.

Based on the three logical implications identified and examined above, we can now formulate the conclusion that the institutionalism is simply a species of evolutionism. The remaining differences between institutionalism and evolutionism as such (that is, those differences which stay outside the intersection between the spheres of institutionalism and evolutionism) are the following:

(a) institutionalism is an evolutionism deliberatively designed and implemented, based on intellectual projects (in the most part, rationally designed and implemented, although not totally as such); stricto sensu, institutionalism is restricted to human society; however, lato sensu, wherever there are working memes, it should be considered to be also institutionalism, since the memes are institutions too, like semes. Indeed, the human society institutionalism functions based on both semes and memes, but even if only memes exist, the institutionalism is still present (the only difference between semes and memes is that while semes are codified (i.e. formalized), memes are not such); (b) the most important difference between institutionalism and evolutionism is, obviously, the fact that inside institutionalism we have exclusively a Lamarckian evolutionism, while inside evolutionism, alongside Lamarckism, Darwinism is working too;

(c) consequently, institutionalism regards the structure of human (or of non-human, after the case) structure of society, but it regards not, from biological point of view, the living individuals embedded by that society (From biological point of view there is only evolutionism and only based on Darwinism - the vehicle of biological evolutionism is the gene, as wellknown);

(d) however, what about the living individuals in the society as regards their non-biological dimension, that is, regarding their cultural (or, more generally, societal) dimension? For example, what about learning (no matter its nature or ways)? Some considerations on this subject, focused on institutionalism, are provided below:

- in both human and non-human societies, learning is exclusively Lamarckian, no matter which is its vehicle: semes or memes;

- $\quad$ so, from the perspective of institutionalism, the living individuals do not evolve, only develop (unlike in the case of evolutionism, which says, prima facie, the same - individuals develop, species evolves institutionalism forbid the very evolution of species (of course, if, by an extension of language, we do not consider the society as such as being... the species of individuals involved).

\subsection{Political Economics as Institutional Economics}

Political Economics is a discipline (or theory) aimed at to establish the norms, as general required rules of organizing and functioning of the praxiological activity named economic activity. Although, at its ground, Political Economics is not lack of positive knowledge about the economic process To be held that the positive knowledge is (preponderantly) referring to means, while the normative knowledge is (preponderantly) referring to purposes), however, dominantly it is a normative not a positive theory (Dinga, 2012). In this context, Political 
Economics are linked to institutionalism through two main anchors:

- by proposing to society principles and norms regarding its general normative framework aimed at to provide an economic activity/process in accordance with the purpose of this activity/process, not only with its means (as orthodox Economics does);

- by establishing the norms regarding its own development and adequacy to the general path of society's becoming.

Thus, it seems enough obvious that Political Economics is, de jure, as well as de facto, of institutional nature, since establishing norms means establishing institutions in their most extended signification. In other words, the Institutional Economics cannot develop without embedding Political Economics. Likewise, Political Economics cannot develop without the framework of Institutional Economics. One could put the question whether, so staying the things, there is anymore some differences between Political Economics and Institutional Economics. I think there remain certain differences as follows:

Institutional Economics massively focuses on the role of institutions in generating, maintaining, and assessing both economic process and economic results, while Political Economics aspires to design the economic process based on the normed economic results. This difference is a natural outcome of the fact that Political Economics has before eyes especially the outcomes, while Institutional Economics has before eyes the whole economic phenomenology;

(ii) Institutional Economics sees the institutions (i.e. norms) per se, that is, as a „machine” to design, implement, and drive the economic process, without (too much) value judgments, while Political Economics is primarily preoccupied by the ethical signification of the economic results and, based on them, by the ethical signification of the means triggered.

Precisely based on the remained differences between Institutional Economics and Political Economics, we can say that Political Economics is a species of Institutional Economics and that, principled, a genuine Institutional Economics should structurally integrate Political Economics.

\subsection{Institutional Economics as Evolutionary Economics}

Based on the result already obtained before, namely that institutionalism is a species of evolutionarism, (Hodgson, 1999) I shall try now to logically "transfer" this results in order to show that Institutional Economics is a species of Evolutionary Economics.

First of all, it must be noted that all four branches of economic theory (that is: Economics, Political Economics, Institutional Economics, Evolutionary Economics) are "alive" and engage many scientists across the world. As any institutionalism is, logically, an evolutionarism, it results the Institutional Economics is an Evolutionary Economics too, but, of course, the inverse implication is not (totally) true, because there are some properties of Evolutionary Economics which are not verified by Institutional Economics, for example:

- Evolutionary Economics mandatorily must establish a mechanism of replication of its phenotype (which, in turn, implies to establish the genotype, the mutations, the self-reflexivity and so on); of course, such a phenotype must be identified and defined or, at least, described. All these are not mandatorily for Institutional Economics, instead;

- So, Institutional Economics constitutes itself as a subset of the set called Evolutionary Economics (Nelson et al., 2018). But here arises an...evolutionary question: should Institutional Economics, even as a sub-set of Evolutionary Economics, develop autonomously from the latter? I think no, because:

inherently, the institutional framework of society must change, either as effect of the pressure of society functioning or as effect of its own logic; so, the evolutionary profile of the Institutional Economics cannot be avoided at all;

(ii) this change implies, in fact and generally, simply a replication mechanism, that is, evolution of the institutional framework of the economic process and phenomenology, which leads again to the evolutionary perspective.

In my opinion, researchers in the matter should integrate the finds out of Political Economics into Institutional Economics, and further, the finds out of the latter into the Evolutionary Economics. Finally, it would be of hoping to be edified a robust evolutionary theory of Economics as an auto-poietic theory as the economic process and phenomenology is, in fact (Hamilton et al., 2009).

\subsection{On a tetrad of economic theory}

Thus, we come to a tetrad of economic theory that needs to be clarified and systematized so that we have a general economic theory as an evolutionary one. This path and end can be synoptically suggested as in Figure 5 below. 


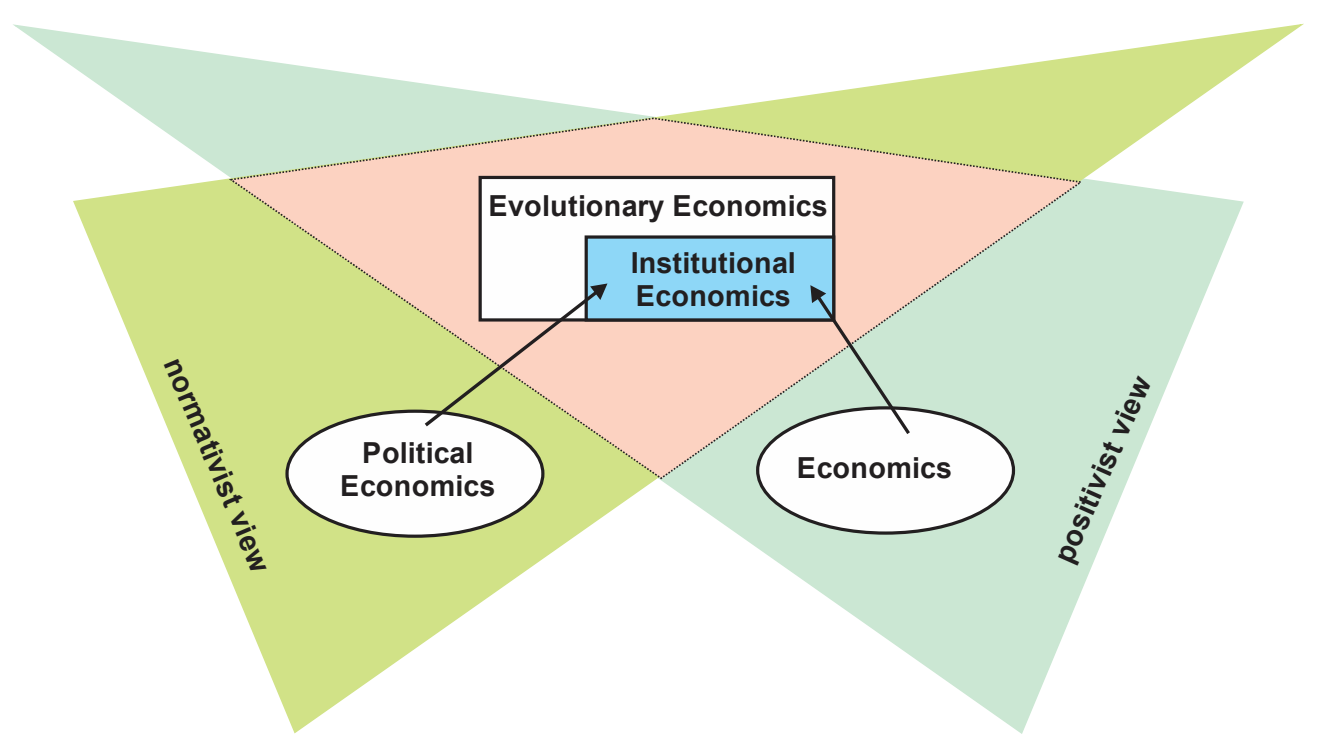

Figure 5. Tetrad of economic theory wings

Source: author

\section{RESULTS AND CONCLUSIONS}

The institutionalism, as pattern of human (and, maybe, of "endowed" with non-human individuals) society, is, in fact and as role, a species of the evolutionism. This is proved above by using the logical relationships between the sufficient predicates of institutionalism and of evolutionism, respectively. By particularizing method, the Institutional Economics must be seen as a species of the Evolutionary Economics (of course, there are other "species" in Evolutionary Economics which are not of the Institutional Economics nature). In turn, Institutional Economics integrates Economics as (preponderantly) positive economic theory and Political Economics as (preponderantly) normative economic theory. As desirability it seems productive (and I believe even inherent) the Institutional Economics, as formed by the contribution of Economics and Political Economics, be developed as Evolutionary Economics, more precise, as an auto-poietic economic theory (possible to be based on the seminal suggestions made by Winter and Nelson, for economic theory, and by Luhmann, for social theory).

\section{REFERENCES}

1. Aruka, Y. (2001) Evolutionary controversies in economics: A new transdisciplinary approach. Springer Science \& Business Media.

2. Dinga, E. (2012) Rebuilding Economics. Logical, Methodological and Epistemological Approach. Saarbrucken, Germany: Lambert Academic Publishing.

3. Hamilton, D. et al. (2009) Cultural Economics and Theory: The Evolutionary Economics of David Hamilton. Routledge. doi: 10.4324/9780203869840.

4. Hamilton, D. (2017) Evolutionary Economics: A Study of Change in Economic Thought. 1st edition. Routledge.

5. Hodgson, G. M. (1999) 'Evolution and institutions', Books.

6. Hodgson, G. M. (2004) The Evolution of Institutional Economics. Routledge. doi: 10.4324/9780203300350. 